\title{
The introduction of a targeted next generation sequencing diagnostic service for $\mathrm{MH}$
}

\author{
Dorota Fiszer ${ }^{1 *}$, Sarah Hobson ${ }^{1}$, Nickla Fisher ${ }^{2}$, Marie-Anne Shaw ${ }^{1,2}$, Sarah Shepherd', Rachel Robinson', \\ Ruth Charlton', Phil Hopkins, ${ }^{1,2}$ \\ From 33rd Annual Meeting of the European Malignant Hyperthermia Group (EMHG) \\ Wurzburg, Germany. 15-17 May 2014
}

\section{Background}

In this paper we describe how we sought approval and are implementing a diagnostic service for malignant hyperthermia $(\mathrm{MH})$ using clonal targeted next generation sequencing.

Approval required submission of a gene dossier to the UK Genetic Testing Network. This document included:

1. An overview of $\mathrm{MH}$ and the evidence for involvement of RYR1 and CACNA1S;

2. Details of the genes

3. Current diagnostic approaches

4. Proposed sequencing strategy

5. Gene coverage with proposed strategy

6. Validation strategy

7. Genetic epidemiology of $\mathrm{MH}$

8. Test characteristics (sensitivity, specificity, PPV, NPV)

9. Cost benefit of new test

10. Referral criteria

Following adoption of the dossier by the UGTN and validation of the sequencing strategy in a diagnostic facility, we are now in a position to offer testing. Testing will be offered to families where $\mathrm{MH}$ has been confirmed by IVCT and to new index cases. The cost of the sequencing is $£ 530$, compared to $£ 3,500$ for the IVCT. For index cases, the referring physician will be advised of the pre-test probability for their patient having $\mathrm{MH}$ as they may consider IVCT to be more cost-effective when the pre-test probability is low.

Diagnostic reports will be issued in accordance with the joint guideline of the UK Association of Clinical
Table 15 Class System

\begin{tabular}{lll}
\hline Class & Description & Interpretation \\
\hline 1 & Clearly not pathogenic & $\begin{array}{l}\text { MH not confirmed or } \\
\text { excluded }\end{array}$ \\
2 & Unlikely to be pathogenic & $\begin{array}{l}\text { MH not confirmed or } \\
\text { excluded }\end{array}$ \\
3 & $\begin{array}{l}\text { Variant of unknown significance } \\
\text { (VUS) }\end{array}$ & $\begin{array}{l}\text { MH not confirmed or } \\
\text { excluded }\end{array}$ \\
4 & Likely to be pathogenic & $\begin{array}{l}\text { Consistent with diagnosis } \\
\text { Confirms diagnosis }\end{array}$ \\
5 & Clearly pathogenic & \\
\hline
\end{tabular}

Genetic Science (ACGS) and the Dutch Society of Clinical Genetic Laboratory Specialists (VKGL). Variants will be classified using a 5 class system:

Reports for classes $1-3$ will advise IVCT.

Variants will be assigned to a class depending on their reported frequency in databases (dbSNP, 1000 Genomes, EVS), segregation analysis and functional analysis.

\section{Authors' details \\ 'Leeds Institute of Biomedical \& Clinical Sciences, School of Medicine, University of Leeds, Leeds, LS9 7TF, UK. ${ }^{2}$ Malignant Hyperthermia Investigation Unit, St James's University Hospital, Leeds, LS9 7TF, UK.}

Published: 18 August 2014

doi:10.1186/1471-2253-14-S1-A14

Cite this article as: Fiszer et al: The introduction of a targeted next generation sequencing diagnostic service for $\mathrm{MH}$. BMC Anesthesiology 2014 14(Suppl 1):A14. 